\title{
Job Insecurity and Mental Well-Being in Finland, Norway, and Sweden
}

\section{Consequences of Flexicurity in a Nordic Welfare Setting}

I Patrik Vulkan'

Doctoral Candidate, Department of Sociology and Work Science, University of Gothenburg, Sweden

I Antti Saloniemi

Professor, School of Social Sciences and Humanities, University of Tampere, Finland

I Jørgen Svalund

Researcher, Fafo Institute for Labour and Social Research, Norway

I Anna Väisänen

Master of Social Science, School of Social Sciences and Humanities, University of Tampere, Finland

\begin{abstract}
This article describes how the flexicurity arrangement of low job security, high employment security, and good income security advocated by various authors affects the mental well-being of employees. Data are derived from a survey carried out in 2010-201 I among employees in Finland, Norway, and Sweden. The main findings are that all three forms of cognitive security (the perceived risk) have an independent effect on mental well-being and that the worry of insecurity (the affective component) mediates the relationship with mental well-being. The interaction effects show that high levels of employment security can alleviate the detrimental effects of job insecurity on mental well-being. No similar interaction effect was found with job insecurity and income security. The results are discussed in relation to the institutional arrangements of the Nordic countries' welfare states, concluding that the high employment security needed for a successful flexicurity arrangement requires either low levels of unemployment or effective and extensive active labor market programs. Flexicurity is thus susceptible to economic turmoil and requires further labor market investments, even in the Nordic countries.
\end{abstract}

\section{KEY WORDS}

Flexicurity / job insecurity / mental well-being / employment security / income security / cognitive and affective insecurity

\section{Introduction}

D esearchers are increasingly examining job insecurity and its consequences for employees in flexible labor markets (Cheng and Chan 2008). The present study contributes to the field by analyzing how a potential increase in job insecurity

\footnotetext{
${ }^{1}$ Patrik Vulkan, Department of Sociology and Work Science, Box 720, 40530 Göteborg, Sweden. Email: patrik.vulkan@socav.gu.se
} 
relates to mental well-being among employees and whether any negative consequences can be reduced by the presence or interaction of employment or income security. We differentiate between cognitive and affective insecurity in our analysis, allowing us to better understand whether the perception of high insecurity by an employee in a given situation actually relates to poor mental well-being (Anderson and Pontusson 2007; Greenhalgh and Rosenblatt 1984; Huang et al. 2012). By taking into account three forms of insecurity and their interaction, in conjunction with both cognitive and affective components, we contribute by providing a new multidimensional model of job insecurity.

This study is a systematic comparison of Finland, Norway, and Sweden with regard to the different forms of insecurity in the labor market, using data collected in 20102011. We consider the institutional arrangements relevant to the discussion of flexicurity in the three welfare states as important contextualization of employees' experience of insecurity and security (Chung and Van Oorschot 2010; Mau et al. 2012). Several studies identify the Nordic countries as having employment regimes that combine flexibility and security, in which the risk of increased job insecurity in flexible labor markets is compensated by employment and income security, thereby reducing detrimental results for employees (cf. Muffels and Luijkx 2008; Muffels et al. 2014). As such, Finland, Norway, and Sweden are relevant cases for examining the potential outcomes of a compensatory arrangement. ${ }^{1}$

The next section outlines the implementation of flexicurity policies in labor markets and their consequences for employees' well-being. Theories regarding relationships between mental well-being and insecurity, and how employment and income security provide means to alleviate the consequences of job insecurity, are then reviewed. This review is followed by a description of institutional welfare arrangements relevant to the discussion and presentations of the acquired data, analytical methods, and analysis of the results. The article ends with a concluding discussion.

\section{Flexicurity and job insecurity}

The concept of flexicurity, as advocated by Wilthagen and Tros (2004) and others (Madsen 2004, 2006; Muffels et al. 2008) is a well-known proposal for achieving flexibility in labor markets without detrimental insecurity. It suggests that we need to view security in the labor market as composed of job, employment, and income security, rather than simply job security, in order to achieve an optimal balance between security for employees and flexibility for employers. Excessive employment protection is considered a hindrance to numerical flexibility by employers and a crucial area for reform by flexicurity proponents. Weak employment protection is likely to cause job insecurity among employees. However, adverse consequences of this can be avoided, according to flexicurity advocates, through high levels of employment security (opportunities for finding a new job) and income security (abilities to avoid financial hardship during jobless periods). The presence of these two forms of security should supposedly compensate for negative consequences stemming from job insecurity such as mental ill-being. Critics of the flexicurity approach argue that the flexibility and security mentioned are incompatible goals and that the arrangement is simply another form of deregulation of employment protection, which reduces welfare states' protective functions and results 
in insecure jobs and lower salaries (Burroni and Keune 2011; Howell et al. 2007; Ozaki 1999; Tangian 2008). Accordingly, Burchell (2009) finds no evidence that flexicurity policies protect the mental well-being of employees, although the only form of insecurity the cited author specifically analyzed is job insecurity.

From this brief summary of relevant literature, a key question can be formulated: What are the full consequences of job insecurity for the mental well-being of employees? Wilthagen and Tros (2004) suggested a way to address this question in detail by using a more multifaceted concept of security, but this raises another question: 'How does a multidimensional notion of insecurity function and how does it translate into the risk of ill-being?'

The analytical starting points of the present study are the components of job insecurity. Job insecurity is usually considered to be either objective or subjective, the former referring to the actual risk of dismissals and layoffs, and the latter (the focus of this article) to individuals' evaluation of the likelihood of losing their current jobs in the near future (Ellonen and Nätti 2013). Subjective job insecurity is generally defined as being involuntary, in the sense that employees do not actively seek it (De Witte 2005). It should be noted that the same job threat can lead to different experiences of insecurity among employees with different characteristics (De Witte 1999; Sverke and Hellgren 2002). However, the uncertainty of job insecurity may compromise employees' ability to deal with the ongoing situation, since it is unclear what action should be taken. They may thus perceive themselves as powerless to resist the threat (Anderson and Pontusson 2007; Hellgren and Sverke 2003; Lazarus and Folkman 1984; Sjöberg 2010).

The study also addresses job insecurity as a multidimensional phenomenon, with both cognitive and affective aspects (Greenhalgh and Rosenblatt 1984; Huang et al. 2012). The cognitive aspect refers to the employee's estimation of the likelihood of a job loss in the future. While this estimation may be incorrect, there is usually a positive correlation between individuals' assessments of risks and ensuing job losses (Chung and Mau 2014; Dickerson and Green 2012; Klandermans et al. 2010). The affective aspect is the emotional reaction to the estimation of job loss likelihood. Research linking the two aspects has also found that cognitive job insecurity is strongly associated with worry about losing the job (Berglund et al. 2014). Anderson and Pontusson (2007) argued that cognitive job insecurity should be considered an influential determinant of affective job insecurity, but the affective experience also depends on the individual's capacity to handle the risk of job loss or deal with the event (cf. Huang et al. 2010).

\section{Mental well-being}

Job insecurity among employees is negatively related to subjective well-being (Sjöberg 2010; Vulkan 2012). This can be understood as individuals' subjective stress reactions to a state of unpredictability and lack of control. Job insecurity has been shown to be associated with psychological distress, anxiety, and depression as well as mental, emotional, and physical exhaustion. This state has been shown to be as potentially harmful as actual unemployment (Burchell 2011; De Witte 1999; Sjöberg 2010).

Two theories provide a deeper theoretical explanation of the mechanism whereby insecurity affects mental well-being. The first is the classical latent deprivation theory presented by Marie Jahoda (1982), which holds that employment fulfills a manifest 
function, by generating an income, and five latent functions: time structure, social contact, sharing of common goals, status, and activity. In a situation with great risk of unemployment the latent functions are held to be the main factors explaining the negative effect on mental well-being, with the risk of unemployment implying the obstruction and deprivation of these current needs (Creed and Bartrum 2006; Ervasti and Venetoklis 2010). However, none of these authors offer indications of the relative explanatory importance of the latent functions. The second is agency restriction theory, developed by David Fryer, which is complementary to Jahoda's theory. It treats individuals as:

socially embedded agents who are actively striving for purposeful determination, attempting to make sense of, initiate, influence and cope with events in line with personal values, goals, expectations of the future in a context of cultural norm, traditions and past experience. (Fryer 1995)

The disruption of plans and strategies caused by insecurity severs individuals from a meaningful future if they lack, or are obstructed from, effective strategies to deal with insecurity, leading to mental ill-being. Consequently, it is not work in itself that causes this but hindrance of the ability to plan and control one's own life that work can fulfill. This theory stresses the manifest function as the explaining mechanism, with the potential loss of income and threat of poverty rendering the employees unable to deal with insecurity. Each theory suggests a main aspect of insecurity affecting mental well-being, while recent research on insecurity among Swedish employees indicates that manifest and latent functions are of approximately equal explanatory value (Vulkan 2012).

\section{Employment and income security as means to alleviate job insecurity}

Job insecurity in itself is considered detrimental for well-being, but can be countered by the presence of employment security and income security according to flexicurity theory (Wilthagen and Tros 2004). Employment security is the possibility of finding a new job; knowing that you will be able to find a new job if the need arises should lessen the insecurity associated with losing a specific job. This concept of employment security is similar to the strongly related concept of perceived employability, but it usually stresses a structural or institutional, rather than individualistic, view of the labor market (cf. Berglund et al. 2014; Berntson 2008; Garsten and Jacobsson 2004; Silla et al. 2009). Employment security is believed to be enhanced by institutional arrangements such as lifelong learning institutions and active labor market policies, as well as a dynamic economy in general (Berglund and Furåker 2011). Important antecedents to employment security are age, education, and tenure. Generally, young people believe they have better employment opportunities than old people and those with higher education generally have better chances of finding a new job of equal or better value, which also translates into a more positive outlook (Furåker 2010b). Regarding tenure, there seems to be a 'lock-in' effect, i.e., length of tenure and employees' beliefs that they could find a new job seem to be negatively correlated (Berglund et al. 2014).

Employees can also attain income security, usually through unemployment insurance or other institutional arrangements for social security intended to ensure that financial needs are met during a period of unemployment. Income security is assumed to ease 
the burden of unemployment and facilitate a smooth process of return to work, thus acting as a compensating mechanism for job insecurity in the flexicurity arrangement (Berglund et al. 2014; Muffels et al. 2014). Income security has also been found by Sjöberg (2010) to enhance employees' mental well-being directly by reducing the uncertainty connected to becoming unemployed and providing insurance against unforeseen economic hardships (cf. Carr and Chung 2014).

These two forms of security can be understood as means for mitigating consequences of job insecurity and should, according to proponents of flexicurity, negate the adverse effect on mental well-being. Employment security and, to a lesser extent, income security are both associated with a lower degree of anxiety (affective job insecurity) among employees and we expect the presence of these two forms of security to be related to improved mental well-being (Berntson and Marklund 2007; Ervasti and Venetoklis 2010; Green 2011; Nordenmark et al. 2006; Vulkan 2012). Employment security and income security are also treated as multidimensional phenomena, with both cognitive and affective aspects (cf. Vulkan 2012), in the present study.

We thus anticipate an interaction effect between cognitive job insecurity and employment security, reducing the impact of cognitive job insecurity on mental well-being. Earlier research (cf. Berglund et al. 2014) has shown that employees are less worried if cognitive job insecurity is combined with employment security than the additive effects of these factors would suggest. Thus, high levels of employment security mitigate worry associated with the anticipated risk of a job loss. A similar interaction effect between cognitive job insecurity and cognitive income security could be possible, but previous research has not found significant effects on worries to support this (Berglund et al. 2014). Moreover, we predict that affective job insecurity should decrease the interaction effect between cognitive job insecurity and employment security by acting as a mediator between cognitive job insecurity and mental well-being (Vulkan 2012).

\section{Institutional arrangements in the three Nordic countries}

To further contextualize the results, we examine the institutional frameworks that research has found to affect the different forms of security and insecurity at play. In line with the key components of flexicurity, we describe the focal countries in terms of indicators of the institutional arrangements most likely to affect security (Chung and Mau 2014): employment protection legislation (EPL), active labor market programs (ALMP), and unemployment benefits (UBs). The unemployment level is also presented since it affects the performance of the aforementioned factors in the labor market. Contextualization by focusing on the institutional arrangements can help us understand variations in the results. Moreover, findings that the results remain the same despite institutional variations between the three countries would corroborate our key argument that there are strong relationships between the considered forms of security and well-being. The data presented in this section are based on information reported by official bodies of the three countries to the OECD, as shown in Table 1 and associated endnotes. The presented indicators show the institutional arrangements in 2010 or as close as possible to this year.

To evaluate the three countries' EPL, which is likely to influence job insecurity (Anderson and Pontusson 2007; Chung and Van Oorschot 2010), we use the measure of 
Table I Summary of employment-related measures for the three countries

\begin{tabular}{|c|c|c|c|c|c|}
\hline & \multicolumn{2}{|c|}{ EPL $(20 \mid 0)^{2}$} & \multirow{2}{*}{$\operatorname{ALMP}(2009)^{3}$} & \multirow{2}{*}{ UB $(20 \mid 0)^{4}$} & \multirow{2}{*}{$\begin{array}{l}\text { Unemploymen } \\
(2010)^{5}\end{array}$} \\
\hline & Regular & Temporary & & & \\
\hline Finland & 2.38 & 1.88 & 0.11 & 0.53 & 8.5 \\
\hline Norway & 2.23 & 3.04 & 0.14 & 0.64 & 3.7 \\
\hline Sweden & 2.52 & 0.79 & 0.13 & 0.47 & 8.7 \\
\hline OECD mean & 2.13 & 2.06 & 0.06 & 0.57 & 8.5 \\
\hline
\end{tabular}

EPL strictness developed and applied by the OECD concerning legislation for employees in regular employment and temporary employment. Collective agreements between employers and employees are also taken into account (OECD 2013; Venn 2009). The measure for both forms of employment is a scale from 0 to 6, with a high number indicating strict EPL. Regarding EPL for regular employees, all countries have similar strictness scores, although the Swedish score is slightly higher than the Norwegian and Finnish scores. These figures have been constant for some years. EPL strictness for temporary employment shows clear differences, being high for Norway, intermediate for Finland, and very low for Sweden. In the Swedish case, new legislation was enacted in 2007 that allowed a greater degree of fixed-term contracts (Nordic Council of Ministers 2010). Consequently, EPL strictness was reduced to almost half its previous value. Such institutional changes are notable, since in themselves they can affect the well-being of employees (Lübke and Erlinghagen 2014). In summary, while the protection for permanent employees is quite similar in all three countries, EPL strictness for temporary employees differs greatly across the Nordic countries.

ALMP is likely to affect employment security, especially if unemployment is high (Chung and Van Oorschot 2010). Thus the proportion of Gross Domestic Product (GDP) spent on ALMP per percentage point of unemployment is used as an indicator of the ambitiousness and prioritization of ALMP (Berglund and Furåker 2011). Levels of ALMP investment relative to the unemployment level are quite similar in all three countries. The absolute amount of GDP invested in Norway is smaller, but due to a low level of unemployment, the relative amount is higher. Unemployment fell in all three countries from 2005 until 2009 then rose again. Over the same time, the amount of GDP spent on ALMP has been constant in Finland and declined somewhat in Norway and Sweden, although it is still well above the OECD mean.

UB, which is likely to influence income security (Chung and Mau 2014), is measured here using the net replacement rates of an average wage for a single household with no children during the initial phase of unemployment. Reported rates are lowest in Sweden, intermediate in Finland, and most generous in Norway. The Norwegian replacement rate has been stable over the last decade. The Finnish replacement rate decreased from $61.5 \%$ in 2002 to $50.7 \%$ in 2008 , but has subsequently increased. The Swedish replacement rate has diminished since 2002 when it was $67.5 \%$, drastically so since 2006 when the new Conservative government reduced the generosity of the UB system (Bengtsson and Berglund 2012). It should also be noted that unemployment insurance is mandatory in Norway, but following the Ghent system, voluntary in Finland and Sweden (cf. Scruggs 2002). 
To summarize the institutional setting in the three countries, Finland, Norway, and Sweden emerge as similar with respect to ALMP. EPL for regular employees and unemployment levels are similar in Finland and Sweden, although Sweden has a lower UB replacement rate and weaker EPL for temporary employees. In comparison to both Finland and Sweden, Norway has slightly weaker EPL for regular employees, but much stricter EPL for temporary workers, and a more generous UB system. Furthermore, Norway has a significantly lower unemployment level than the other two countries. All these factors are likely to result in higher levels of mental well-being among Norwegian employees.

\section{Survey data and methodology}

The data concerning the various forms of security and insecurity used in this article were collected using three separate, but similar, questionnaires designed specifically for the study and sent to employees in Sweden (autumn 2010), Finland (winter 2010-2011), and Norway (spring/summer 2011). The ordinary Labor Force Survey (LFS) was used as a sampling framework. For comparative reasons, we used the age group 19-64 years in the analysis. The response rates were $40 \%$ in Norway (1,634 responses), $53 \%$ in Finland (2,252 responses), and 54\% in Sweden (2,023 responses). Young people under the age of 24, the temporarily employed, and, in Finland, men are overrepresented among the non-respondents. These groups have been further analyzed with regard to potential selection bias, but no deviations of note have been found. The further drop in response rate that can be observed in the regression analyses is mainly due to removing nonresponses from the security and insecurity variables.

The dependent variable is mental well-being, which has been operationalized using a modified version of General Health Questionnaire 12 (GHQ-12), a commonly used measure of individual psychological well-being. The instrument targets two areas - the inability to carry out normal functions and the appearance of distress - to assess a person's wellbeing (Goldberg and Williams 1988). Each respondent is instructed to answer how they have been feeling during the past few weeks, by agreeing or disagreeing with statements about their mental well-being. We used Finnish, Norwegian, and Swedish translations of GHQ-12, and modernized the wording of some questions. For all 12 items there was a four-point Likert response and scoring system $(0-3)$ in the Finnish and Swedish versions, while there was also a fifth, middle alternative in the Norwegian version. GHQ-12 is widely used as a unidimensional instrument and a factor analysis shows that all 12 questions work well as single scales ( $\alpha=0.898$ in Finland, $\alpha=0.888$ in Norway, and $\alpha=0.866$ in Sweden). The scale ranges from 0 to 36 (the Norwegian range was rescaled from 0-48 to 0-36), with higher values indicating better mental well-being. The unidimensionality and high alpha value of the Norwegian GHQ-scale are strong indications that the difference in scale points does not result in a qualitatively different construct compared to Finland and Sweden.

Table II Cognitive and affective dimensions included in the article

\begin{tabular}{lccc}
\hline & Job insecurity & Employment security & Income security \\
\hline Cognitive dimension & $X$ & $\times$ & $\times$ \\
\hline Affective dimension & $X$ & & $X$ \\
\hline
\end{tabular}


The dimensions of security and insecurity comprising the focal independent variables are shown in Table 2. Questions that could effectively gauge affective employment security were not included in the surveys at the time of construction.

Cognitive job insecurity is measured by the question 'How do you assess the risk that, in the coming 12 months, you are going to lose your job?' The first option includes 'Very large' and 'quite large,' the second consists solely of 'neither large nor small,' the third includes 'quite small' and 'very small.' Respondents who chose the fourth option, 'Don't know,' were excluded from subsequent analyses.

Affective job insecurity is measured by the question 'To what extent do you worry about losing your present job?' 'I worry a great deal' and 'I worry to a certain extent' are grouped as the first response option, while 'I worry a little bit' and 'I do not worry at all' are treated as separate options. Norwegian respondents could also answer 'no opinion'; they were excluded from subsequent analysis.

Cognitive employment security is measured by the question 'In general, what do you think of your current opportunities for finding another job that is equal or better than your current job?' with the answers 'good' and 'quite good' grouped as the first response option, 'neither good nor poor' as the second, and 'quite poor' and 'very poor' as the third.

Cognitive income security is measured by the question 'How would you/your household manage economically if you became unemployed and had to rely on unemployment benefits for between 3 and 6 months?' with the answers 'Very well' and 'Quite well' making up the first response option, 'Neither well nor poorly' the second, and 'Quite poorly' and 'Very poorly' the third. In Norway, the respondents could also answer 'I don't know.' These respondents were excluded from subsequent analysis. Note that the respondent might share their financial responsibilities with other people. Previous research has shown that manifest and latent functions of work affect mental health within 6 months, thus our chosen time span seems reasonable for the question (Selenko and Batinic 2013).

Affective income security is measured by the question 'In general, do you worry about your/your household's economy?' Due to events beyond our control certain response options differ between the countries. The answers 'I worry a great deal' and 'I worry to some extent' make up the first option. The second option consists of 'I do not worry much' for the Finnish and Swedish respondents and 'Neither a lot nor a little' for the Norwegian respondents. The third response option for the Finnish and Swedish respondents is 'I do not worry at all,' while it consists of two options for the Norwegian respondents: 'I worry to a quite small degree' and 'I worry to a very small degree.' There was also a 'No opinion' category in all countries. Respondents choosing this option were excluded from subsequent analysis.

A central question addressed in the article is whether employment and income security can compensate for job insecurity. This is tested using ordinary least square (OLS) regression analysis, for which the variables are coded in different directions, with job insecurity (both cognitive and affective) measuring insecurity (from low to high), while employment and income security (both cognitive and affective) measure security (from low to high). Thus, the relationships between mental well-being and job insecurity factors are expressed as negative coefficients (as job insecurity is inversely related to mental well-being) while the relationships between mental well-being and employment or income security factors are expressed as positive coefficients (as security is positively related to mental well-being). 
Control variables with a known relationship to either job insecurity or mental wellbeing are also included in the analysis. They include demographic (age and civil status), human capital (occupation and income), and psychosocial (job demand, social support, and job satisfaction) variables (Berntson and Marklund 2007; Chung and Van Oorschot 2010; De Witte 1999, 2005; Ellonen and Nätti 2013; Karasek and Theorell 1990; Keim et al. 2014; Sverke and Hellgren 2002). Job satisfaction reportedly mediates part of the effect of job insecurity on mental well-being, but also has a unique effect on mental wellbeing (Chirumbolo and Hellgren 2003). In order to control for the latter it is necessary to include job satisfaction as a control variable, but we do not expect this to result in an overadjustment risk. For parsimonious presentation, control variables showing no significant relationship with mental well-being are not included in the results displayed here. These variables are gender, educational level, working hours, employment contract, number of employees at workplace, tenure, and sector.

The analysis starts by describing distributions of the focal independent variables (Table 3), allowing a country comparison. Three OLS regression models are then used to estimate effects of the independent variables (Table 4). The first focuses on how the cognitive variables relate to the subjective mental well-being of employees, the second includes the affective variables, while the control variables are also included in the third model.

Finally, interaction effects of job insecurity and employment security on mental well-being are estimated (Table 5). The first model here shows interaction effects of the relevant cognitive variables. While not shown in the table, the control variables are also included at this point. In Model 2, the relevant affective variable is included, to measure to what extent the cognitive interaction effect on mental well-being is mediated through it. The interaction between cognitive job insecurity and cognitive income insecurity was also tested, but yielded no significant results, which are therefore not shown. All findings mentioned below are significant at a probability level of at least 0.05 .

\section{Results}

As shown in Table 3, employees in Finland report relatively high levels of cognitive job insecurity. Unemployment rates are similar in Finland and Sweden, and although EPL for regular employees does not differ much between these countries, a higher proportion of Finnish employees perceive a great risk of losing their job. The same pattern occurs with regard to affective job insecurity, with Finnish employees reporting to a larger extent than Swedish employees that they worry about losing their job. The lowest levels of affective job insecurity are found in Norway, as expected considering its low level of unemployment and relatively strict EPL.

Concerning cognitive employment security, employees in Norway perceive a smaller risk of not finding a new job than employees in Finland and Sweden. Swedish and Finnish respondents exhibit greater levels of polarity, with large proportions of employees perceiving the opportunities as either very good or very poor.

With regard to cognitive income security, a higher proportion of Swedish employees than either Finnish or Norwegian employees stated that they would manage well economically during unemployment, which is surprising considering that Swedish employees have the lowest replacement rate. In sharp contrast, in terms of affective 
Table III Frequency table of insecurity variables (\%)

\begin{tabular}{|c|c|c|c|}
\hline & $\begin{array}{c}\text { Finland } \\
(n=\min 2,099 \\
\max 2,196)\end{array}$ & $\begin{array}{c}\text { Norway } \\
(n=\min 1,489, \\
\max 1,573)\end{array}$ & $\begin{array}{c}\text { Sweden } \\
(\mathrm{n}=\min \mathrm{I}, 872, \\
\max 1,993)\end{array}$ \\
\hline \multicolumn{4}{|l|}{ Cognitive Job Insecurity } \\
\hline Very or quite large risk of job loss & 10.6 & 3.4 & 5.4 \\
\hline Neither large nor small risk & 16.3 & 6.6 & 9.9 \\
\hline Very or quite small risk & 73.1 & 90.1 & 84.7 \\
\hline \multicolumn{4}{|l|}{ Affective Job Insecurity } \\
\hline $\begin{array}{l}\text { Worry a great deal or to some } \\
\text { extent about job loss }\end{array}$ & 10.0 & 4.8 & 9.0 \\
\hline Worry a little bit & 27.0 & 18.7 & 17.3 \\
\hline Do not worry at all & 63.0 & 76.6 & 73.7 \\
\hline \multicolumn{4}{|l|}{ Cognitive Employment Security } \\
\hline $\begin{array}{l}\text { Very or quite good opportunities } \\
\text { of finding a new job }\end{array}$ & 35.7 & 37.5 & 35.9 \\
\hline $\begin{array}{l}\text { Neither good nor poor } \\
\text { opportunities }\end{array}$ & 25.2 & 33.1 & 27.1 \\
\hline Very or quite poor opportunities & 39.1 & 29.4 & 37.0 \\
\hline \multicolumn{4}{|l|}{ Cognitive Income Security } \\
\hline $\begin{array}{l}\text { Would manage very or quite well } \\
\text { economically during unemployment }\end{array}$ & 41.8 & 43.5 & 49.7 \\
\hline Neither well nor poorly & 26.2 & 27.2 & 23.0 \\
\hline Very or quite poorly & 32.0 & 29.4 & 27.3 \\
\hline \multicolumn{4}{|l|}{ Affective Income Security } \\
\hline $\begin{array}{l}\text { Do not worry at all about my/my } \\
\text { household's economy }\end{array}$ & 18.3 & 62.6 & 30.0 \\
\hline Worry a little bit & 44.3 & 23.8 & 49.9 \\
\hline $\begin{array}{l}\text { Do worry a great deal or to some } \\
\text { extent }\end{array}$ & 37.4 & 13.5 & 20.1 \\
\hline
\end{tabular}

income security, $62.6 \%$ of the Norwegian respondents reported that they do not worry at all about their, or their household's, economy, whereas corresponding percentages for Swedish and Finnish respondents were $30.0 \%$ and just $18.3 \%$, respectively. A larger percentage of Finnish employees also reported that they worry a great deal or to some extent. The Norwegian results should be interpreted with some caution, since the difference in wording of the response options could explain some of the results. Affective income security refers to worry about 'your/your household's economy,' and may reflect economic aspects beyond the scope of this article, for instance economic responsibilities encompassing varying numbers of individuals, the presence and scale of household debt, 
and possibilities that people may receive external financial support, for example from parents.

OLS regression (Table 4) is used to estimate specific significant effects of independent variables. In Model 1, cognitive job insecurity has the expected effect on mental well-being in all three countries, with poorer mental well-being reported among employees perceiving a large risk of losing their job. Among Finnish respondents, unexpectedly, the group perceiving neither a large nor small risk of job loss report poorer mental well-being than the group reporting a large risk of job loss. Employment security has the expected relationship in Finland and Sweden: those with good perceived opportunities of finding a new job report better mental well-being than those with poor perceived opportunities. In Norway, there is no significant effect of employment security on mental well-being according to this model. Income security shows the expected relationship in all three countries, with those perceiving that they would manage well having better mental well-being.

In Model 2, we include the affective variables, and expect to find evidence that they act as mediating variables between the cognitive variables and mental well-being. Generally, the results seem to confirm this expectation. In Norway and Sweden, affective job insecurity is negatively related to mental well-being and the distinct effect of cognitive job insecurity is noticeably weakened in all three countries by the large covariation between the two variables. This indicates that affective job insecurity acts as a mediator.

The same pattern also holds true for income security. Affective income security is positively related to mental well-being, while the effect of cognitive income security is much weaker than in Model 1 and hardly significant. The effect of affective income security may potentially relate to more than UBs (the variable used to estimate cognitive income security here). Nevertheless, affective income security seems to act as a mediating variable, not only for cognitive income security but also for cognitive job insecurity (separate analysis not shown), indicating that the risk of unemployment is directly related to economic worries. Cognitive employment security still has a unique effect on mental well-being in Finland and Sweden, showing that including all three forms (job, employment, and income) is relevant when researching links between security and mental well-being.

The results for cognitive income security among Finnish employees seem to be contrary to expectations in Model 2, as negative coefficients indicate that those stating they would manage well during a period of unemployment report poorer mental well-being than those stating that they would not manage well. This occurs when we introduce affective income insecurity, and indicates a suppressed relationship (cf. Aneshensel 2002). Thus, there are two tendencies in the Finnish data regarding cognitive income security, with a strong effect on mental well-being in the expected direction and a weaker effect in the opposite direction. In Model 1 this weaker tendency is suppressed by the stronger tendency, but it emerges when we introduce affective income insecurity (for reasons that are currently unclear).

The general pattern still holds after introducing the control variables in Model 3. Both affective variables still exhibit a unique (but weaker) effect on mental well-being. This now also includes affective job insecurity among Finnish employees. Most of these effects do not significantly differ between the countries, suggesting that the processes involved are not specific to one country. Examining the cognitive variables, job insecurity is not significant in any of the countries except in the aforementioned category 


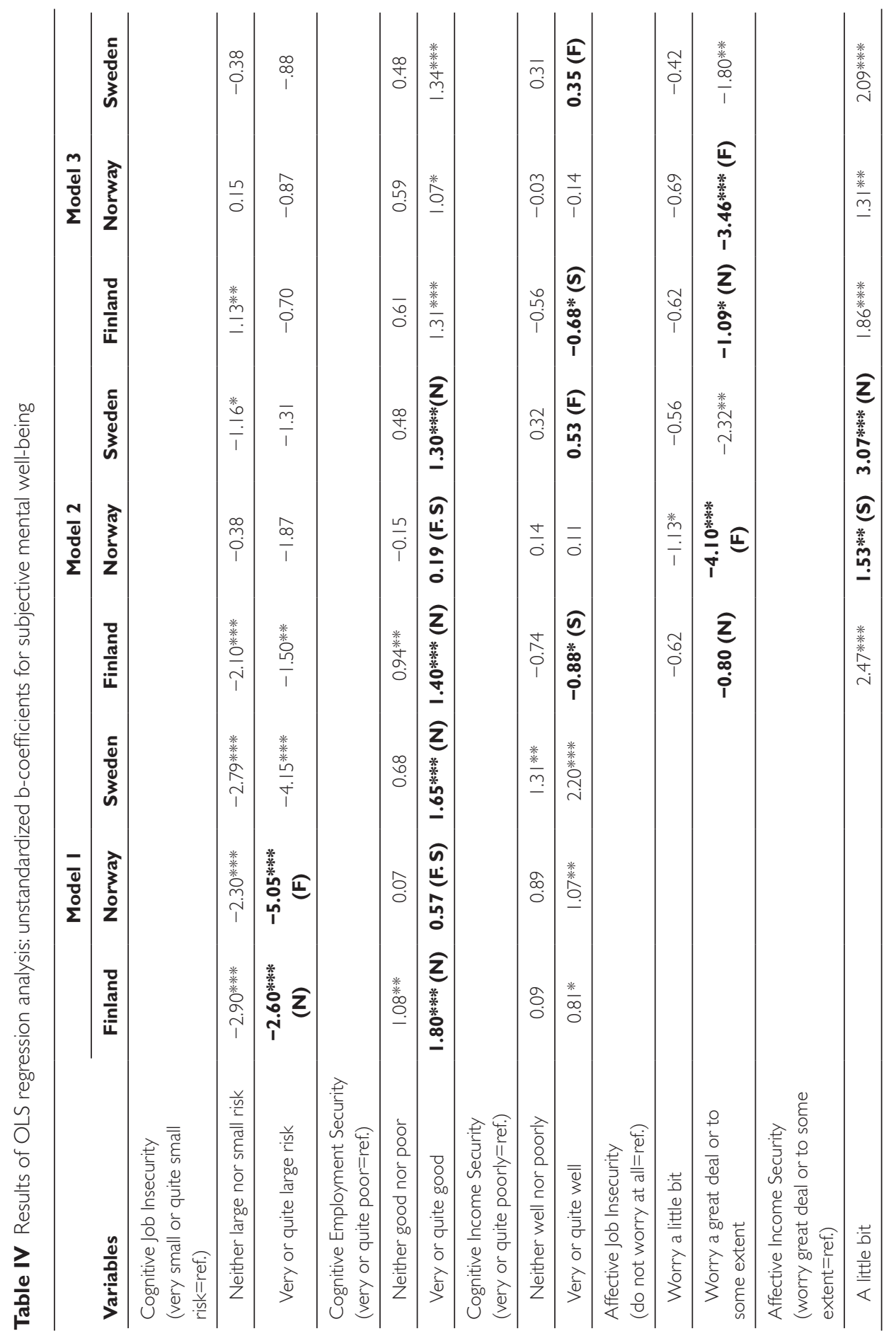




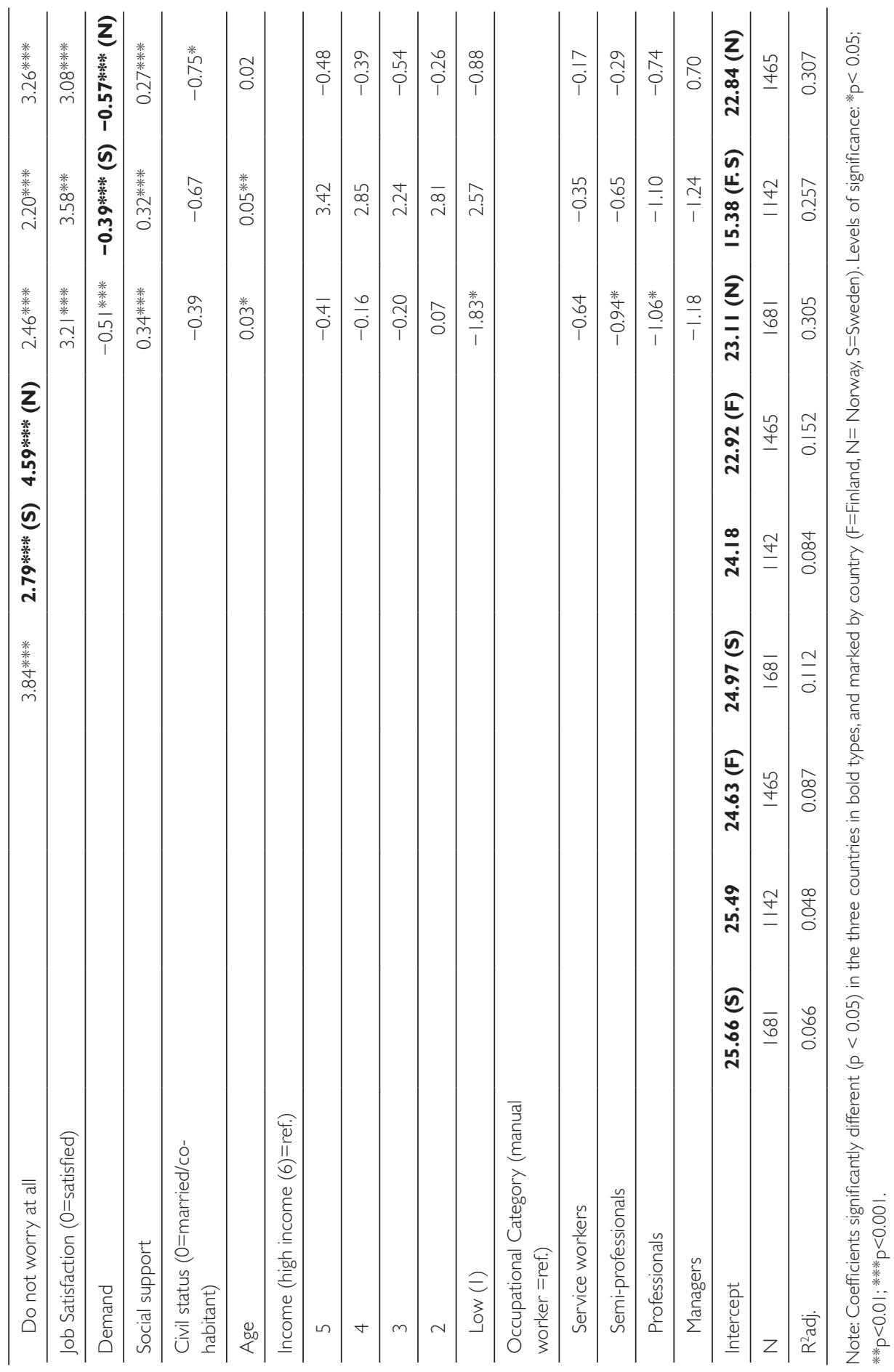


in Finland. The remainder of the effect after controlling for the affective variable now co-varies with the control variables. Cognitive employment security now shows a significant effect on mental well-being in all three countries. This indicates another suppressed relationship, in Norway, which emerges when the control variables are included. Employment security per se has an important relationship with mental well-being, but we should allow for the possibility that this may be due to reversed causality, i.e., that employees who report poor mental well-being may (consequently) see smaller chances of finding a new job (Furåker 2010a). Cognitive income security shows no significant effect except in Finland, due to the weakening of its effect by the suppressed relationship. Regarding control variables, Model 3 shows that job satisfaction, job demand and social support are all strongly related to mental well-being. These relationships were expected and act to further isolate effects of the security variables. Most of the other control variables have minor or insignificant effects on mental well-being.

To investigate the detected interaction effects (shown in Table 5), we start by examining Model 1, which was used to study effects of the cognitive variables and interaction effects. Included, but not shown, are all of the other variables from Table 4 to further isolate effects of the security variables on mental well-being. The main results from Model 1 are also presented in Figure 1.

The reference category consists of the interaction effect between low job insecurity and low employment security. The aim is to emulate the combination of securities usually accredited to the Nordic model; high job security but also low employment security (resulting in low flexibility), and its relationship to mental well-being. This allows us to compare how interactions between high job insecurity and various levels of employment security fare in relation to the reference category, thereby testing how the combination of securities suggested in the flexicurity arrangement relates to mental well-being.

For Norwegian employees, perceiving a large risk of losing the current job while also perceiving a small chance of finding a new job is related to a substantial reduction in mental well-being score (more than 8 points). In comparison, those who also perceive a large chance of finding a new job of equal or better value report a small (1.2 point) increase in mental well-being. For those who perceive a large risk of losing their job, but neither a large nor small chance of finding a new job, mental well-being decreases by almost 2 points. The results are consistent with previous findings (Berglund et al. 2014), illustrating that high levels of employment security can provide the means to deal with the detrimental effects of job insecurity on mental well-being. These findings are interesting with regards to the claim by flexicurity proponents that employment security under the right conditions should offset the negative relationship between job insecurity and mental well-being, successfully relating flexicurity with well-being.

Looking at the results for Finnish employees, the interaction between high job insecurity and low employment security is related to a 2-point reduction in mental wellbeing score, compared to the reference interaction. However, high employment security in combination with high job insecurity is related to an increase of 1.4 points. Among Swedish employees, perceiving a large risk of job loss and a small chance of finding a new job is related to a 4.5 -point reduction in mental well-being score, compared to the reference interaction. The interaction with high employment security is related to a mental well-being score of 0 , indicating that the combination of securities suggested in the flexicurity arrangements does not differ in its relationship to mental well-being from the interaction of low job insecurity and low employment security. 


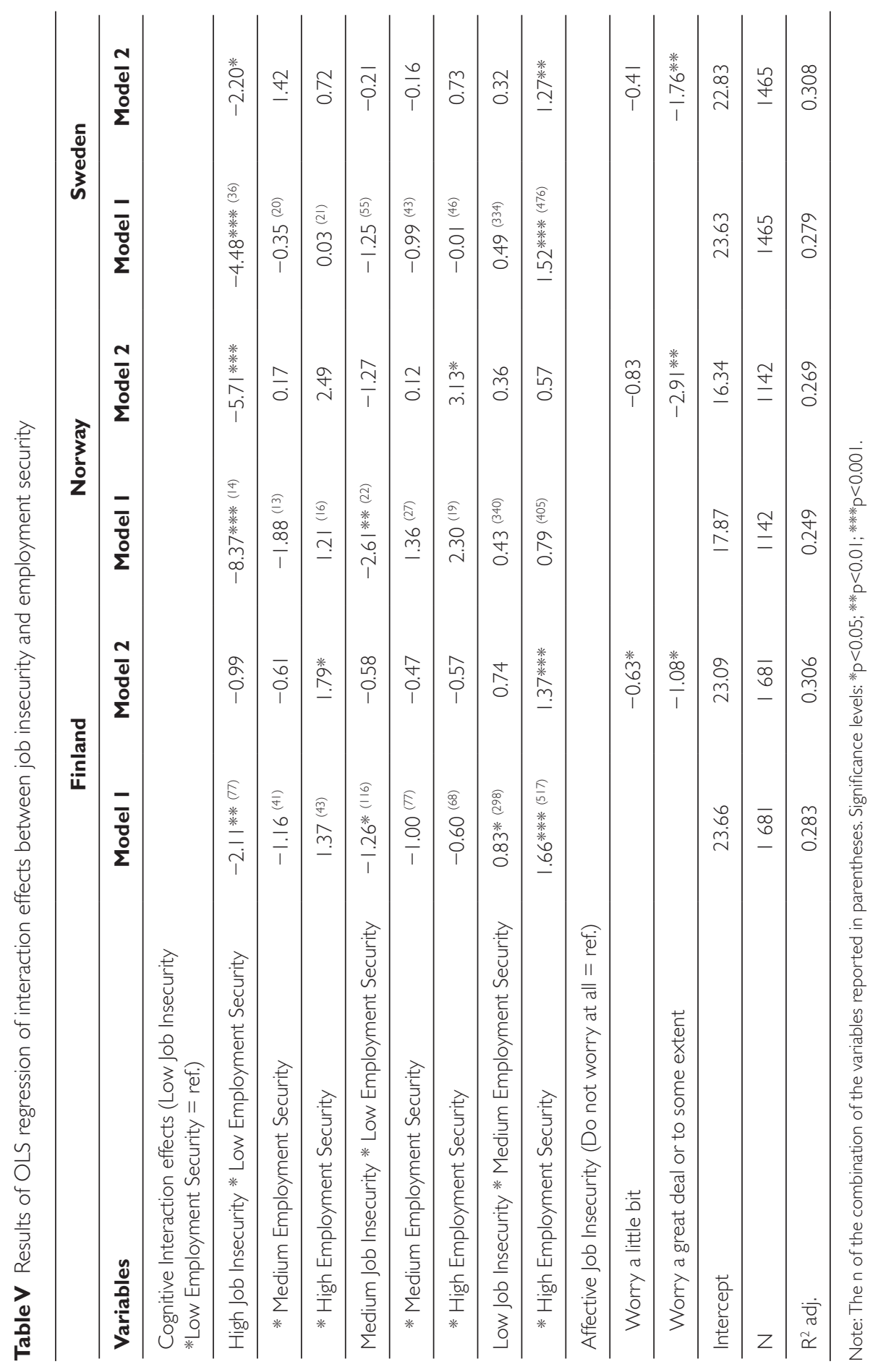


Figure I: Effects of the interaction between high job insecurity and employment security (categorized as low, medium, and high) compared to the reference category 0 (low job insecurity and low employment security) on mental well-being.
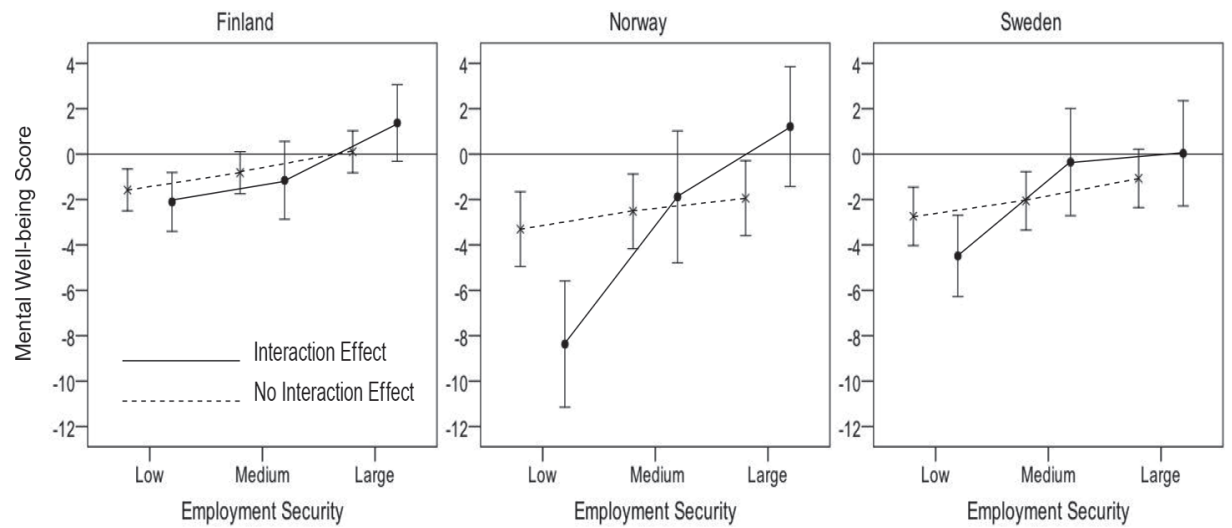

When affective job insecurity is introduced in Model 2, the significant effect of the interaction is still present in most of the cases, showing that the cognitive interaction remains, even when controlling for the affective dimension.

Figure 1 illustrates the value of including the interaction effects in a multiplicative model rather than in a purely additive model. The horizontal reference line at 0 shows the mental well-being score associated with the reference category of low job insecurity and low employment security, while the plotted points show scores (relative to the reference) associated with combinations of high job insecurity and the three levels of employment security in each country (and confidence intervals of the scores).

The apparent relationship between job insecurity and employment security is more modest if the interaction effects are excluded. Including the interaction effects reveals a more nuanced and divergent pattern, showing that the relationship with mental wellbeing is not only more negative when employment security is low, but also more positive when employment security is high. Several of the interactions are based on data from quite small groups of respondents, as reported in Table 5, but the confidence intervals show that the interaction effects between high and low employment security differ significantly in all three countries.

The interaction effects are clearly relevant when trying to discern how insecurity relates to mental well-being. They also indicate that flexicurity arrangements could compromise employees' mental well-being. Under favorable conditions such arrangements could have positive effects on mental well-being, but a lack of appropriate employment security in a flexicurity arrangement is clearly related to much lower levels of well-being.

\section{Concluding discussion}

The presented results show that the tested components of security (job, employment, and income) are related to mental well-being in Finland, Norway, and Sweden. While 
the three countries' institutional arrangements share some similarities, there are also differences among them, and this suggests that the processes involved are not specific to one country, and highly important for understanding how the well-being of employees relates to insecurity.

All of the three main forms of security and insecurity are independently related to well-being and all three are of analytical importance. These results underline the need to view job insecurity as a multidimensional phenomenon. Employment and income security provide means for mitigating job insecurity, since they are related to better well-being. Each offers a distinct strategy to deal with an insecure situation. Income security corresponds to Fryer's theory of agency restriction, which holds that the main source of poor well-being is the lack of control and planning resulting from insufficient financial resources. Employment security corresponds more closely to Jahoda's theory of the latent functions of employment. This suggests that future employment, and associated prospects of fulfilling the general latent functions, in itself can act as a viable way to mitigate the consequences of job insecurity. We come to this conclusion because we control for economic aspects using income security and the particular combination of latent functions found in the current job through job insecurity. Both ways should thus be considered when discussing means to deal with job insecurity.

This leads us to the question as to whether these forms of security can fully negate the impact of job insecurity on mental well-being, as suggested in flexicurity theory. Burchell (2009) argues that there is no empirical evidence to support this. The results obtained from our multidimensional model indicate that the flexicurity strategy could function effectively as proposed, provided that appropriate forms of institutional arrangements are in place. High perceived levels of employment security seem to counter even high levels of job insecurity. Thus, flexicurity arrangements could work, but only if employees at risk of unemployment perceive relatively high levels of employment security. Less than $40 \%$ of our respondents fell into this class. This should be compared to the relatively few employees who experience job insecurity. The success of the flexicurity strategy rests on few employees perceiving employment insecurity in the labor market, which is likely to require both low levels of unemployment and successful ALMPs. High demand for labor will probably result in high employment security. Likewise, ALMPs could lead to high employment security even if there is low demand for labor. However, this rests on the premise that the ALMPs include effective measures. Employment security could be achieved by improving the matching of skills to jobs through extensive ALMP measures, but simply relying, for instance, on matching can be problematic during an economic downturn, when there are few available jobs, and the flexicurity arrangement offers few other options for raising employment security during economic decline. The flexicurity arrangement is clearly dependent on successful ALMP measures during periods of low labor demand, corresponding with a previous conclusion that flexicurity does not work well in 'bad weather' (Tangian 2010). Furthermore, extensive ALMP measures are costly and it could prove challenging to find the political support to implement them fully.

Finally, this study clearly illustrates the relationship between the cognitive and affective dimensions. In all three countries both cognitive job insecurity and cognitive income security show a significant relationship with mental well-being that is strongly reduced when the relevant affective aspect is controlled for. This behavior is expected and illustrates the theoretical understanding presented earlier, that the cognitive perception of risk generally translates into the affective experience of worry. 
Our study setting has limitations that need to be overcome with new approaches and further research. Using cross-sectional data, we cannot definitively elucidate the causal relationships between the variables, for this more research in the field using panel data is required. Research on security in general, and flexicurity in particular, in the Nordic welfare states would also benefit from including Denmark, as it provides a prime example of a labor market characterized by flexicurity. It would also be useful to include the level of unemployment as a control variable, to see how it relates to insecurity in the three countries. It should also be mentioned that a more restricted definition of affective income security would be useful, since the one used in this article may potentially relate to economic factors beyond the intended individual or household. Further questions that warrant attention include the generalizability of the results beyond the Nordic welfare states, and potential differences in the focal relationships elsewhere.

\section{Acknowledgments}

The authors thank the following research funding bodies for financing the study: The Finnish Work Environment Fund, The Norwegian Research Council's research program on welfare, working life and migration (VAM) and the Swedish government agency VINNOVA.

\section{References}

Anderson CJ and Pontusson J (2007) Workers, worries and welfare states: Social protection and job insecurity in 15 OECD countries. European Journal of Political Research 46: 211-235.

Aneshensel CS (2002) Theory-Based Data Analysis for the Social Sciences. Thousand Oaks: Pine Forge.

Bengtsson M and Berglund T (2012) Labour market policies in transition: From social engineering to standby-ability. In: Larson B, Letell M and Thörn H (eds) Transformations of the Swedish Welfare State: From Social Engineering to Governance? Houndmills, Basingstoke: Palgrave Macmillan, pp. 86-103.

Berglund T and Furåker B (2011) Flexicurity institutions and labour market mobility. The International Journal of Comparative Labour Law and Industrial Relations 27: 111-127.

Berglund T, Furåker F and Vulkan P (2014) Is job insecurity compensated for by employment and income security? Economic and Industrial Democracy. 35(1): 165-148.

Berntson E (2008) Employability Perceptions: Nature, Determinants, and Implications for Health and Well-Being. Stockholm: Stockholm University.

Berntson E and Marklund S (2007) The relationship between perceived employability and subsequent health. Work \& Stress 21: 279-292.

Burchell B (2009) Flexicurity as a moderator of the relationship between job insecurity and psychological well-being. Cambridge Journal of Regions, Economy and Society 2: 365-378.

Burchell B (2011) A temporal comparison of the effects of unemployment and job insecurity on wellbeing. Sociological Research Online. 16(9). Available at: www.socresonline.org. uk/16/1/9.html (accessed October 10, 2014).

Burroni L and Keune M (2011) Flexicurity: A conceptual critique. European Journal of Industrial Relations 17: 75-91. 
Carr E and Chung H (2014) Employment insecurity and life satisfaction: The moderating influence of labour market policies across Europe. Journal of European Social Policy 24(4): 383-399.

Cheng $\mathrm{G}$ and Chan D (2008) Who suffers more from job insecurity? A meta-analytic review. Applied Psychology: An International Review 57: 272-303.

Chirumbolo A and Hellgren J (2003) Individual and organizational consequences of job insecurity: A European study. Economic and Industrial Democracy 24(2): 217-240.

Chung H and Mau S (2014) Subjective insecurity and the role of institutions. Journal of European Social Policy 24(4): 303-318.

Chung H and Van Oorschot W (2010) Employment insecurity of European individuals during the financial crisis: A multi-level approach. Working Papers on the Reconciliation of Work and Welfare in Europe (REC-WP) 14.

Creed PA and Bartrum D (2006) Explanations for deteriorating wellbeing in unemployed people: Specific unemployment theories and beyond. In Kieselbach T, Winefield AH, Boyd $\mathrm{C}$ and Anderson S (eds.) Unemployment and Health. International and Interdisciplinary Perspectives. Brisbane: Australian Academic Press.

De Witte H (1999) Job insecurity and psychological well-being: Review of the literature and exploration of some unresolved issues. European Journal of Work and Organizational Psychology. 8: 155-177.

De Witte H (2005) Job insecurity: Review of the international literature on definitions, prevalence, antecendents and consequences. Journal of Industrial Psychology 31: 217-240.

Dickerson A and Green F (2012) Fears and realisations of employment insecurity. Labour Economics 19(2): 198-210.

Ellonen N and Nätti J (2015) Job insecurity and the unemployment rate: Micro- and macro-level predictors of perceived job insecurity among Finnish employees 1984-2008. Economic and Industrial Democracy. 36(1): 57-71.

Ervasti $\mathrm{H}$ and Venetoklis T (2010). Unemployment and subjective well-being. An empirical test of deprivation theory, incentive paradigm and financial strain approach. Acta Sociologica. 53(2): 119-138.

Fryer D (1995) Benefit agency? Labour market disadvantage, deprivation and mental health. The Psychologist. June: 265-272.

Furåker B (2010a) Inlåsning på den svenska arbetsmarknaden [Lock-in effects in the Swedish labour market]. Arbetsmarknad \& Arbetsliv 16(4): 55-70.

Furåker B (2010b) Job insecurity and job change prospects. Views among Employees in Sweden with a focus on youth. In: Blanpain R, Bromwich W, Rymkevich O and Spattini S (eds) Labour Productivity, Investment in Human Capital and Youth Employment. The Netherlands: Kluwer Law International BV, pp. 3-21.

Garsten C and Jacobsson K (2004) Learning to be employable: An introduction. In: Garsten C and Jacobsson K (eds.) Learning to be Employable: New Agendas on Work, Responsibility and Learning in a Globalizing World. Basingstoke: Palgrave Macmillan, pp. 1-22.

Goldberg D and Williams P (1988) A User's Guide to the General Health Questionnaire. Windsor: NFER-Nelson.

Green F (2011) Unpacking the misery multiplier: How employability modifies the impacts of unemployment and job insecurity on life satisfaction and mental health. Journal of Health Economics 30(2): 265-276.

Greenhalgh L and Rosenblatt Z (1984) Job insecurity: Toward conceptual clarity. Academy of Management Review 9(3): 438-448.

Hellgren J and Sverke M (2003) Does job insecurity lead to impaired well-being or vice versa? Estimation of cross-lagged effects using latent variable modeling. Journal of Organizational Behaviour 24: 215-236. 
Howell DR, Baker D, Glyn A and Schmitt J (2007) Are protective labor market institutions at the root of unemployment? A critical review of the evidence. Capitalism and Society 2: $1-71$.

Huang G, Lee C, Ashford S, Chen Z and Ren X (2010) Affective job insecurity: A mediator of cognitive job insecurity and employee outcomes relationships. International Studies of Management and Organization 40(1): 20-39.

Huang G, Niu X, Lee C and Ashford S (2012) Differentiating cognitive and affective job insecurity: Antecedents and outcomes. Journal of Organizational Behaviour 33: 752-769.

Jahoda M (1982) Employment and unemployment: A social-psychological analysis. Cambridge: Cambridge University Press.

Karasek R and Theorell T (1990) Healthy Work: Stress, Productivity, and the Reconstruction of Working Life. New York: Basic Books.

Keim A, Landis R, Pierce C and Earnest D (2014) Why do employees worry about their jobs? A meta-analytic review of predictors of job insecurity. Journal of Occupational Health Psychology. 19(3): 269-290.

Klandermans B, Hesselink JK and Van Vuuren T (2010) Employment status and job insecurity: On the subjective appraisal of an objective status. Economic and Industrial Democracy. 31(4): 557-577.

Lazarus RS and Folkman S (1984) Stress, Appraisal, and Coping. New York: Springer.

Lübke C and Erlinghagen M (2014) Self-perceived job insecurity across Europe over time: Does changing context matter? Journal of European Social Policy 24(4): 319-337.

Madsen PK (2004) The Danish model of flexicurity: Experiences and lessons. Transfer: European Review of Labour and Research 10: 187-207.

Madsen PK (2006) How can it possibly fly? The paradox of a dynamic labour market in a Scandinavian welfare state. In: Campbell J, Hall J and Pedersen O (eds) National Identity and the Varieties of Capitalism: The Danish Experience. Montreal: McGill-Queen's University Press, pp. 321-355.

Mau S, Mewes J and Schönek N (2012) What determines subjective socio-economic insecurity? Context and class in comparative perspective. Socio-Economic Review 10: 655-682.

Muffels R and Luijkx (2008) Labour market mobility and employment security of male employees in Europe: 'trade-off' or 'flexicurity'? Work, Employment and Society 22(2): 221-242.

Muffels R, Chung H, Fouarge D, Klammer U, Luijkx R, Manzoni A, Thiel A and Wilthagen T (2008) Flexibility and Security over the Life Course. Report for the European Foundation for the Improvement of Working and Living Conditions. 8 February. Dublin.

Muffels R, Crouch C and Wilthagen T (2014) Flexiblity and security: National social models in transitional labour markets. Transfer 20(1): 99-114.

Nordenmark M, Strand M and Layte R (2006) The impact of unemployment benefit system on the mental well-being of the unemployed in Sweden, Ireland and Great Britain. European Societies 8(1): 83-110.

Nordic Council of Ministers (2010). Labour Market Mobility in Nordic Welfare States. Nordic Council of Ministers, TemaNord 2010: 515.

OECD (2013) Protecting jobs, enhancing flexibility: A new look at employment protection legislation. In Keese M (ed.) OECD Employment Outlook 2013. Paris: OECD Publishing, pp. 65-126.

Ozaki M (1999) Negotiating Flexibility: The Role of the Social Partners and the State. Geneva: ILO.

Scruggs L (2002) The Ghent system and union membership in Europe, 1970-1996. Political Research Quarterly 55(2): 275-297.

Selenko E and Batinic B (2013) Job insecurity and the benefits of work. European Journal of Work and Organizational Psychology 22(6): 725-736. 
Silla I, De Cuyper N, Gracia FJ, Peir JM and De Witte H (2009) Job insecurity and well-being: Moderation by employability. Journal of Happiness Studies 10(6): 739-751.

Sjöberg O (2010) Social insurance as a collective resource: Unemployment benefits, job insecurity and subjective well-being in a comparative perspective. Social Forces 88: 1281-1304.

Sverke M and Hellgren J (2002) The nature of job insecurity: Understanding employment insecurity on the brink of a new millennium. Applied Psychology: An International Review 51: 23-42.

Tangian A (2008) Is Europe ready for flexicurity? Empirical evidence, critical remarks and a reform proposal. Intereconomics 43: 99-111.

Tangian A (2010) Not for bad weather: Flexicurity challenged by the crisis. ETUI Policy Brief, Issue 3, Brussels.

Venn D. (2009) Legislation, collective bargaining and enforcement: Updating the OECD employment protection indicators. Available at: www.oecd.org/els/workingpapers.

Vulkan P (2012) Labour market insecurity: The effects of job, employment and income insecurity on the mental well-being of employees. Revista Internacional de Organizaciones 9:169-188.

Wilthagen T and Tros F (2004) The concept of 'flexicurity': A new approach to regulating employment and labour markets. Transfer: European Review of Labour and Research 10: $166-186$.

\section{End note}

1 Danish employees and arrangements were also covered in the original study design, but lack of funding for a Danish survey prevented their inclusion.

2 OECD (2013) Employment protection legislation: Strictness of employment protection legislation: overall. Index 3, OECD Employment and Labour Market Statistics (database). doi: 10.1787/lfs-data-en (accessed on October 14, 2014).

3 OECD (2013) Social expenditure: Aggregated data. OECD Social Expenditure Statistics (database). doi: 10.1787/data-00166-en (accessed on October 14, 2014).

4 OECD (2013) Tax-benefit models, http://www.oecd.org/els/soc/benefitsandwagestax-benefitcalculator.htm (accessed on October 14, 2014).

5 OECD (2013) Unemployment rate. Employment and Labour Markets: Key Tables from OECD. doi:10.1787/20752342 (accessed on October 14, 2014). 